\title{
Vibration and Control in Structures under Single and Multiple Hazards
}

\author{
Aly Mousaad Aly, ${ }^{1}$ Elena Dragomirescu, ${ }^{2}$ Jiming Xie, ${ }^{3}$ and M. A. Hariri-Ardebili ${ }^{4}$ \\ ${ }^{1}$ Louisiana State University, Baton Rouge, LA 70803, USA \\ ${ }^{2}$ University of Ottawa, Ottawa, ON, Canada \\ ${ }^{3}$ Zhejiang University, Hangzhou, Zhejiang Province 310058, China \\ ${ }^{4}$ University of Colorado Boulder, Boulder, CO 80309, USA
}

Correspondence should be addressed to Aly Mousaad Aly; aly@lsu.edu

Received 18 October 2017; Accepted 18 October 2017; Published 12 November 2017

Copyright (C) 2017 Aly Mousaad Aly et al. This is an open access article distributed under the Creative Commons Attribution License, which permits unrestricted use, distribution, and reproduction in any medium, provided the original work is properly cited.

Vibrations in civil engineering structures and mechanical systems arise from different sources of excitations including natural hazards induced loadings of structures, machineries and devices, rotating unbalance, and fault bearings. The field of vibration and control is developed into a multidisciplinary thematic which encompasses knowledge from structural dynamics, modelling, modal analysis, electrical engineering, computer sciences, and control theory, crucial for the understanding and treatment of the issues raised from occurrence of excessive vibrations.

Wind and seismic loads in civil engineering structures, and mechanical unbalance in machines, pose the potential for damage and, if not properly addressed, they can result in loss of life and property. Single and multiple hazards induced forces can wreak catastrophic failure and damage to machines, buildings, and critical infrastructure in general. Consequently, advanced research on vibration analysis and control of structures is vital for the safety and serviceability of the infrastructure under single and multiple hazard loads. Thus, recently, several vibration analysis methods and control techniques are developed and employed in civil and mechanical engineering.

The articles presented in this special issue focus on the state-of-the-art techniques and methods employed in the analysis and control of structures under different types of hazards. This issue comprises analytical methods and experimental investigations and brings vibration and structural control to real world engineering applications.
Unbalanced vibration of the spindle rotor system in highspeed cutting processes seriously affects the surface quality of the machined products. Also, it can greatly reduce the service life of the electric spindle. The contribution "Active Control for Multinode Unbalanced Vibration of Flexible Spindle Rotor System with Active Magnetic Bearing" by X. Qiao and G. Hu proposes an optimal influence coefficient control method with weights for multinode unbalanced vibration of flexible electric spindle rotors.

The active mass dampers are very effective control devices for high-rise buildings, to suppress vibrations under strong winds. In the paper "An Observer-Based Controller with a LMI-Based Filter against Wind-Induced Motion for HighRise Buildings" by C.-J. Chen et al., the authors show that the negative influence of noise in sensors impedes the application of active mass dampers in practice.

The flexibility-based method for modeling shear wall finite element and multi-vertical-line element (SFI-MVLEM) with the method of deleting failure component elements is potential for the understanding of the structural behavior under seismic excitations. The paper "The Performance of Resistance Progressive Collapse Analysis for High-Rise Frame-Shear Structure Based on OpenSees" by Q. Zhang and $\mathrm{Y}$. Li analyzes a frame-shear structure using OpenSees program, based on the nonlinear flexibility theory and multivertical-line theory that considered bending-shear coupling, and its progressive collapse resistance under abnormal conditions. 
Vibration control and energy harvesting can be realized by integrating geometrical and material nonlinear energy sink (NES) with a piezoelectric-based vibration energy harvester under shock excitation. In the work by Y.-W. Zhang et al. entitled "Integration of Geometrical and Material Nonlinear Energy Sink with Piezoelectric Material Energy Harvester," the authors showed that the nonlinear spring and hysteresis behavior of the NES could reflect geometrical and material nonlinearity, respectively.

Despite the fact that most weather-related failures of high-voltage transmission lines (HVTLs) are attributed to downbursts accompanied by heavy rainfall, research works are mainly focused on the behavior of the transmission towerline structures under dry downburst winds. The paper by $\mathrm{C}$. Zhou et al. entitled "Characteristics of Rainfall in Wind Field of a Downburst and Its Effects on Motion of High-Voltage Transmission Line" presents a preliminary study to discuss the characteristics of rainfall in the downbursts and their effects on vibration of HVTLs.

The multiple cardan gyroscope has two rotational degrees of freedom, which can generate strong moments to constrain the two horizontal orthogonal deflections if the rotor operates in high speeds, so the structural dynamic responses can be decreased. The work by H. He et al. entitled "Vibration Control of Tower Structure with Multiple Cardan Gyroscopes" proposes a novel method for the control of tower structures under wind and earthquake loads by using multiple cardan gyroscopes as dampers.

The squeeze film damper (SFD) can enhance the system stability under the bearing fault but the enhancement decreases with the increasing speed. In their paper "Dynamic Analysis of a Rotor-Bearing-SFD System with the Bearing Inner Race Defect," J. Zhang et al. investigate the dynamic behavior of a rotor-bearing-SFD system with the inner race defect of bearing. Their results show that the speed and defect width have different influences on the distribution and amplitude of frequency and the beneficial effect of the SFD varies according to the mounted position in the rotor system.

Structural and damping solutions, including (1) height reduction, (2) steel belts, (3) tuned mass damper, (4) viscous dampers, and (5) orientation change, can be very effective in reducing wind-induced vibrations. In the paper by N. Longarini et al. entitled "Structural Improvements for Tall Buildings under Wind Loads: Comparative Study," the authors investigated the behavior of a very slender building under wind loads, to satisfy both strength and serviceability (comfort) design criteria. The study shows the potential of damping enhancement in slender buildings to mitigate vibrations, reduce design loads, and hence provide an optimal balance among resilience, serviceability, and sustainability requirements.

We hope that this special issue would shed light on recent advances and developments in the area of structural vibration and control for single and multiple hazards and attract attention of the scientific community to pursue further research and studies leading to the rapid implementation of the control devices and methods to create smart, resilient, and sustainable infrastructures which is very important as per current climate change and population growth.

\section{Acknowledgments}

We would like to express our appreciation to all the authors for their informative contributions and the reviewers for their support and constructive critiques in making this special issue possible.

Aly Mousaad Aly

Elena Dragomirescu Jiming Xie

M. A. Hariri-Ardebili 


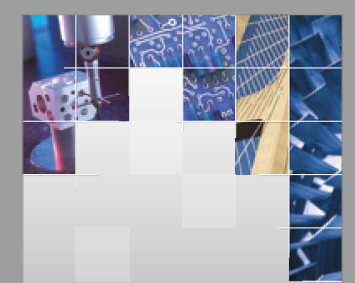

\section{Enfincering}
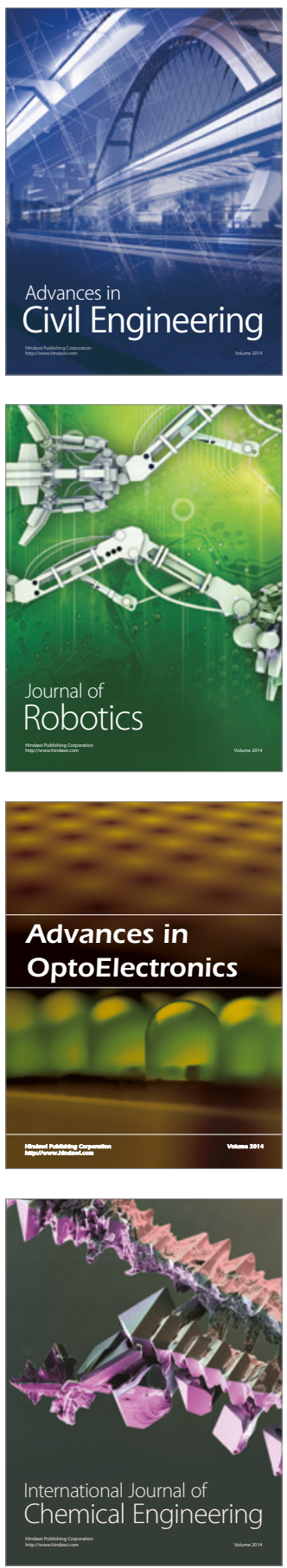

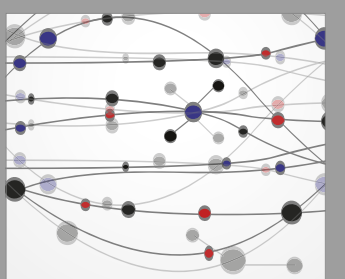

The Scientific World Journal

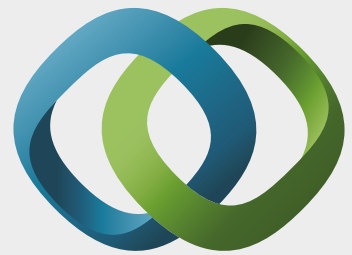

\section{Hindawi}

Submit your manuscripts at

https://www.hindawi.com
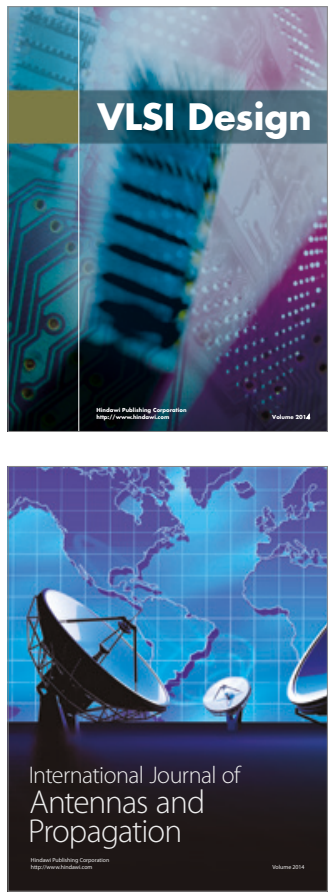

\section{Rotating}

Machinery
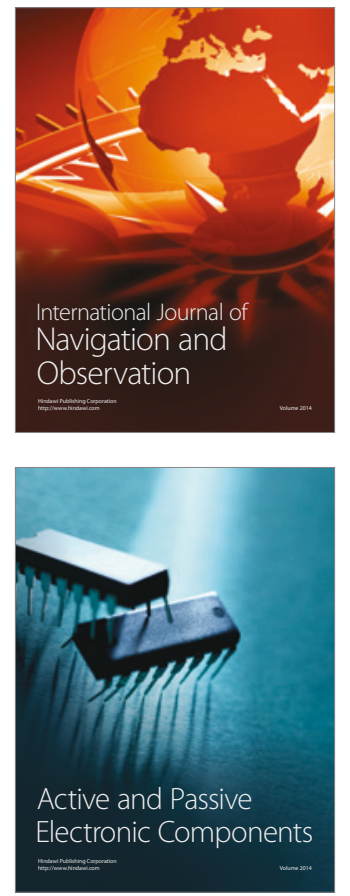
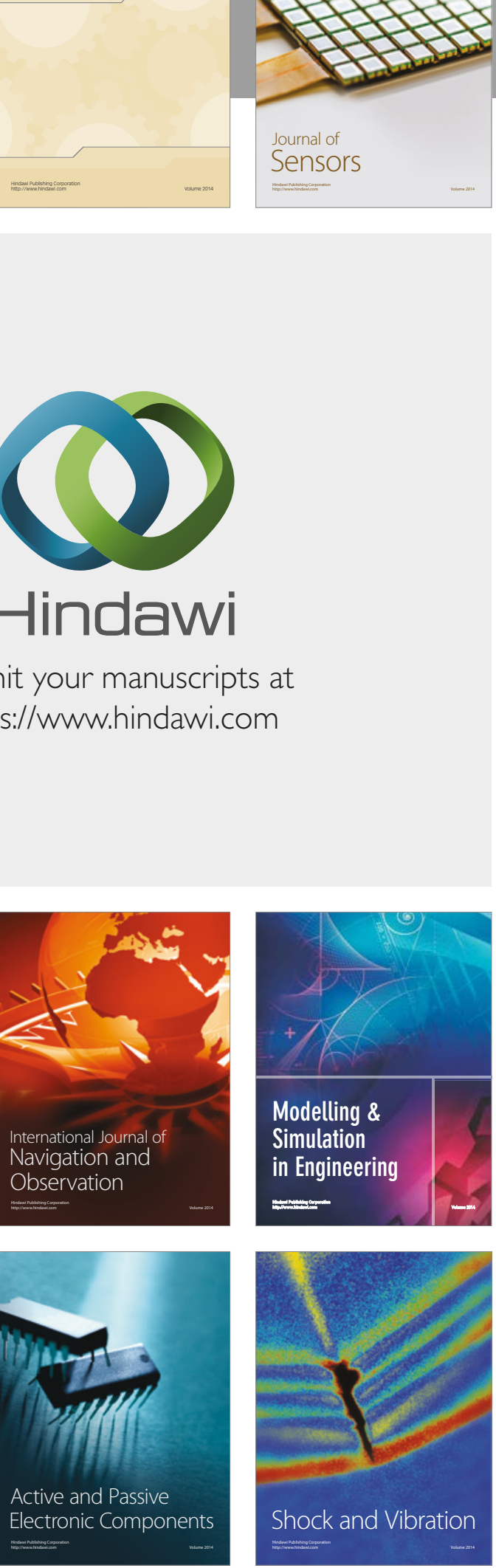
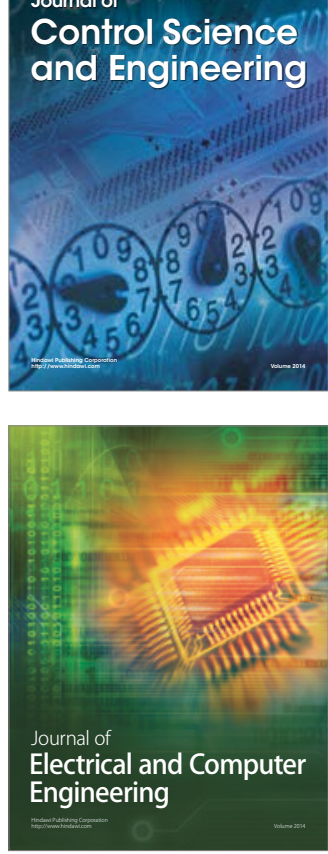

Distributed

Journal of

Control Science

and Engineering
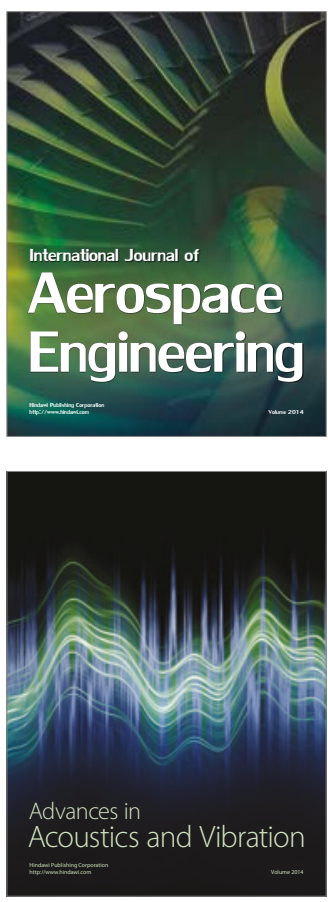

Sensor Networks 